Send your letters to the editor, British Dental Journal, 64 Wimpole Street, London W1G 8YS or by email to bdj@bda.org

Priority will be given to letters less than 500 words long. Letters should be typed. Authors must sign the letter, which may be edited for reasons of space

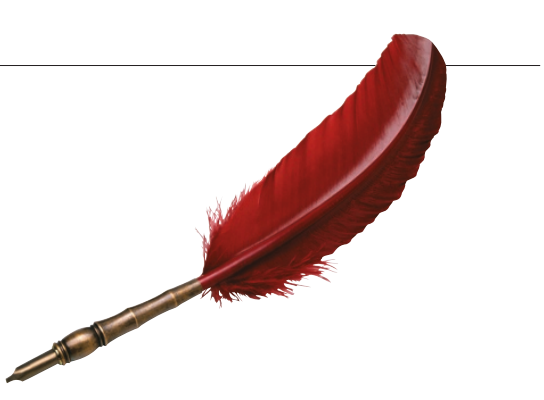

will be all too familiar with the type of situation that I refer to and would welcome any suggestion (however small), which at least attempts to tackle the problem.

\section{A. Raja}

\section{Birmingham}

1. Reekie D, Devlin H. Preventing failed appointments in general dental practice: a comparison of reminder methods. BrDent J 1998; 185: 472-474. 2. www.dentaid.org.

\section{doi: 10.1038/sj.bdj.4811438}

\section{Conscious sedation}

Sir, so conscious sedation is as essential to dentistry as windscreen wipers are to a motorcar (BDJ 2004, 196:138). At this specialist paediatric dental practice we haven't used it for over 25 years - I wondered where we had gone wrong!

In reply to the well-balanced and referenced Opinion article regarding the use of restraint which preceded 'A UK perspective', the author claimed quite selfrighteously and with only one reference, to speak on behalf of UK dentists and UK society at large.

I wonder upon what authority the reply was given to enable this senior dental officer to make his statements; does he have a background in publishing papers on, or the teaching of, behaviour management?

Has he had the good fortune to be taught at first-hand by paediatric dentists with both a wealth of knowledge of the literature of child psychology and also the practice of clinical paediatric dentistry?

There are many references in the literature to show that effective behaviour management for children equates to good parenting techniques. In modern society there is almost certainly a trend towards a more laissez-faire attitude by parents to the discipline of their children and I have to wonder whether this is in reality poor parenting by another name.

Such children fortunately have other significant adults with whom they can interact, for instance teachers and may I dare to venture, dentists. Part of our responsibility is to show children that they are able to cope with anxious situations in life without having to resort to medication to do so. I wonder how often conscious sedation is used by dentists as the easy option, with little regard to not having given the child a chance to develop his inner coping strategies for anxiety. How far does the author venture in his rejection of restraint?

During an administration of local anaesthesia does he never allow the parent, or dental nurse to hold the child's hands, or prevent head movement with his free hand, both of which are examples of restraint?

With pre-cooperative children below the age of three, for the sake of argument, does he never adopt the 'head-in-lap' position, with the parent actively holding (restraining) the child?

How far removed from that situation is it to have the parent at the side of, and holding the hand of, the child wrapped in a blanket or Pediwrap? The fact that I personally do not use Pediwrap does not imply my condemnation of the technique.

There is a wealth of established, wellresearched procedures available to us to help children cope with the stresses of dentistry, and paediatric dentists should have been exposed to all of them during their training. They will thereafter choose to routinely use the methods that they feel comfortable with, but the ones they do not use may be perfectly acceptable to the next. None should be universally condemned.

Now that the grandparenting clause no longer applies, and future entrants to the specialist list of paediatric dentistry should all have received formal training in all aspects of our speciality, one can only hope that the next generation of paediatric dentists will feel confident in managing the behaviour of their young patients.

Perhaps a better reply to the Opinion article would have been to question the poor understanding of child dental behaviour management in the UK, rather than condemn restraint out of hand and universally promote conscious sedation.

\section{J. F. Roberts}

London 
Sir, I am concerned that the well-reasoned article by Dr Kupietzky (BDJ 2004,

196:138) was so dismissively replied to by Dr Manley in the same issue.

The reply seemed to me to be written by someone with little or no knowledge (or even experience of) the behavioural management of children in dentistry and would not represent the opinion of many specialist paediatric dentists in the UK.

A check on Medline does not show any publications by Dr Manley at all, and so one would have to question his authority on the subject. This is in contrast to Dr Kupietzky who has 20 publications in paediatric dentistry of which five concern behaviour management.

The approach to managing the behaviour of children in the dental situation must be based on empathy with a child in order to understand why the child is distressed, anxious or afraid.

Any child's anxiety or fear of dentistry will be manifest in a number of different ways including tears, crying, clinging to

\section{A great opportunity?}

Sir, at a time when NHS practitioners are being offered the chance to get 'off the treadmill' and to provide a better quality of treatment by not being tied to generating fee income, I feel it is totally inappropriate that members of our 'negotiating' team are going round the country advising practitioners that the 'private' sector is the way to go, demonstrating that they themselves are not committed to the NHS.

By persuading dentists into taking the private route they are denying patients the 'right to choose' which I feel is a right all people in a civilised democracy should have.

If the Government, at a time when it is trying to improve working lives of dentists and their teams, were also going round setting up an alternative primary dental care outside the GDS, they would be accused of at the very least duplicity and of not being 'committed' to the changes being proposed.

As a PDS practitioner of three and a half years standing, I can confirm that the new contract is a great opportunity for the profession and that if our negotiators are not committed to the NHS they should step down from their positions and let someone who is committed take their place.

\section{P. M. Ratcliffe \\ Merseyside}

Ian Wylie, BDA Chief Executive responds: One of the strengths of the mother, aggression and physical violence to all around them. The dentist's duty is to determine the reasons behind the child's fear and anxiety and to then use the appropriate behaviour technique to lead the child through a path of gaining attention, the child listening to explanations, understanding, cooperation and then pride in having successfully accomplished their dental care with their dentist.

The child thus learns to cope with a stressful situation within a set of structured guidelines laid down by the dentist.

Any dentist treating children needs a spectrum of behavioural techniques from the simplest - tell and show all the way through to a full general anaesthetic. Within this spectrum lies restraint. Its use is indicated in specific situations and used only when appropriate.

It can be the simplest of hand restraint on a moving arm or head to protect the child from self-harm or to stabilise the

$B D A$ 's position in its discussions with Government over the last three years has been the absolute consistency of its messages to Government.

Negotiators have been able to refer to the BDA policy, both on primary dental care in the 21 st century and also in respect to mixed practice.

These policies were agreed by the Representative Body and have been used as a benchmark for all subsequent discussions.

The Choices Seminars, to which Dr Ratcliffe refers, are consistent with this approach.

They offer dentists, together with their teams, the opportunity to look at the mixed practice environment, in which private care plays a greater role than they have hitherto experienced.

The first series of Choices Seminars proved popular and the content very useful, and further seminars have now been arranged.

At the same time as the NHS component of the mixed practice will remain extremely important to a large number of practitioners, the BDA has concluded its largest ever opinion survey to test the reaction of practitioners to very significant NHS changes being proposed by the Department of Health in England.

The BDA will continue to seek the very best opportunities for its members to practise in the environment they choose, whether that be the NHS, private or, for the large majority, mixed practice.

doi: $10.1038 /$ sj.bdj.4811440 child during operative procedures. But it can also include the use of blankets, sheets or devices specially designed for the purpose.

The recourse to a general anaesthetic should only come after all other avenues of management have been tried.

The question that any dentist who is treating children must ask themselves is whether they should use all behavioural techniques, including restraint, or consign the child to an outpatient general anaesthetic for multiple extractions (it is very unlikely in the UK that such a general anaesthetic would be used for full mouth restoration).

The child is then subjected to a very adverse experience of being put to sleep and waking up feeling awful, retching and spitting blood. Research has shown that far too many people on reaching adulthood can recall such experiences vividly leading to a lifetime of fear of dentistry.

Surely the use of restraint, which is not remembered to the same degree as part of a behavioural management strategy is far better for a child.

In forty years of specialist care of children I have used restraint in all its forms as was appropriate for each occasion. For example, children afflicted with conditions leading to random movement, such as athetoid spasticity, are very well managed with wrapping them up in sheets or papoose boards.

This calms the erratic movements for them, which they very much appreciate. Similarly the tiny infant, just walking, who has fallen over and broken a maxillary incisor is best handled by wrapping (swaddling clothes), so that the broken tooth can be easily and quickly removed.

This avoids a general anaesthetic with all its attendant risks. Of course in the use of restraint there must be informed consent. But this is part of an initial consultation, which a dentist should always take from a parent(s) about their child and how they will, or have in the past, reacted. On this basis the caring dentist discusses with the parent the likely need for various behavioural techniques in his or her management for the child. On occasion this will include restraint.

\section{E. J. Curzon}

Leeds

\section{The author of the article, M. C. G. Manley} responds: I was interested to read the letters from M. E. J.Curzon and J. F. Roberts commenting on an Opinion that I wrote about the article by Kupietzky, recently published in the BDJ 2004, 196: 133. 
The views of the General Dental Council are credible and also representative of $U K$ expert opinion and I would refer them to Maintaining Standards ${ }^{1}$ para 3.10 'There can be no justification for intimidation or, other than in the most exceptional circumstances, for the use of physical restraint in dealing with a difficult patient. When faced with a child who is uncontrollable for whatever reason the dentist should consider ceasing treatment, making an appropriate explanation to the parent or representative and arranging necessary further treatment for the child, rather than continuing in the circumstances'.

This point is also clearly made in the article by C.D.N. Morris 'A commentary on the legal issues' 2 . This author summarises by suggesting that 'any practitioner considering the use of this technique in the UK should seek advice from their defence organisation in the first instance.'

On the subject of behaviour management Roberts suggests that many children who find dentistry an anxiety provoking experience can be treated by behaviour management techniques. There are some children that do not accept treatment for whatever reason using only behaviour management techniques.

The availability of sedation techniques extends the provision of dental care to such groups of children who require support additional to good behaviour management.

These may be children with disability and those who display extremely challenging behaviour.

Both Curzon and Roberts refer to restraint and Roberts in particular within the context of the practice of the reassuring hand, or arm holding. He raises the question of whether this practice should be considered a restraint.

The practice of dentistry inevitably involves physical contact, which may occur in the form of a reassuring holding of the hand or the occasional steadying of an arm or head. This I believe to be a world apart from adopting a policy of using equipment specifically designed to restrain a patient.

With regard to the subject of outpatient general anaesthesia, Curzon states that 'it is very unlikely in the UK that such a general anaesthetic would be used for full mouth restoration'.

This may be so for outpatient general anaesthesia, however over the past twenty four years working in East Kent my weekly programme has involved the provision of a regular day surgery general anaesthesia treatment list including children, for which a range of care is provided including full mouth restoration.
A number of my colleagues working in teaching hospitals and also the Community Dental Service throughout the UK also provide this type of care.

Throughout my experience of treating children under anaesthetic I have, and am currently working with a number of extremely caring anaesthetists who work very hard to ensure that the anaesthetics they administer are provided in a thoughtful manner.

Many children awaken from dental treatment comfortable, relaxed and reassured in the feeling that they are free from dental pain.

The assumption that general anaesthesia is necessarily a traumatic and frightening experience may be as ill founded as the assumption made by Curzon when he refers to the restraint of children with athetoid spasticity, for whom sheets or papoose boards are used.

He tells us 'this calms the erratic movements for them, which they very much appreciate'. Curzon also refers to the tiny infant requiring the treatment of a broken maxillary incisor.

There is no doubt that depending on each clinical case this situation may be best handled without recourse to general anaesthesia, and sedation may also be a useful technique.

He then finally reminds us that we do need consent for treating children and this will follow discussion with the parent/carer. Let us not forget we should also discuss this with the child. The opinion that I wrote can be summarised in five points:

1) Good behaviour management techniques are an essential part of paediatric dentistry.

2) Effective conscious sedation is an extremely valuable technique for the difficult management case.

3) In certain cases the use of general anaesthesia is an essential treatment option.

4) Ineffective sedation with restraint is not an appropriate treatment policy.

5) The policy of using restraint is unacceptable in the UK.

The comprehensive provision of dental care to children from all groups within society necessitates a range of treatment options. If you only have a hammer it is surprising how screws come to look like nails!

\section{C. G. Manley}

By email

\section{doi: 10.1038/sj.bdj.4811439}

1. The General Dental Council. Maintaining StandardsGuidance to Dentists on Professional and Personal Conduct. General Dental Council; 1997.

2. Morris CDN. A commentary on the legal issues. $B D J$ 2004; 196:139-140. 